Revista Brasileira de Farmacognosia Brazilian Journal of Pharmacognosy 22(2): 284-290, Mar./Apr. 2012

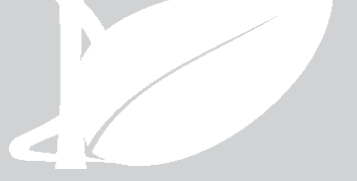

Article

Received 25 May 2011

Accepted 8 Jul 2011

Available online 21 Oct 2011

Keywords:

antioxidant activity

fermented leaves

Lamiaceae

melanoidin

Orthosiphon stamineus

ISSN 0102-695X

http://dx.doi.org/10.1590/S0102-

695X2011005000194

\section{Physicochemical characteristics and antioxidant activity of melanoidin pigment from the fermented leaves of Orthosiphon stamineus}

\author{
Daniil N. Olennikov, ${ }^{*}$ Larisa M. Tankhaeva
}

Laboratory of Medical and Biological Research, Institute of General and Experimental Biology, Siberian Division, Russian Academy of Sciences, Russian Federation.

\begin{abstract}
The melanoidin pigment (OS-M) was isolated from fermented leaves of Orthosiphon stamineus Benth. (Lamiaceae), with a $0.37 \%$ yield (from dry plant weight), and characterised. OS-M is a phenolic polymer with a molecular weight of $4.4 \mathrm{kDa}$. Determination of basic physicochemical parameters using elemental analysis, functional group analysis, UV-Vis- and FTIR-spectroscopy of OS-M indicated that the isolated polymer was similar to typical melanoidins. Experimental data show that aromatic fragments dominate the OS-M structure, which also contains a small amount of aliphatic fragments. Investigation into the antioxidant activity of OS-M under in vitro conditions demonstrated that $O$. stamineus melanoidin has a scavenging effect against free radicals (DPPH $\left.{ }^{*}, \mathrm{ABTS}^{{ }^{+}}, \mathrm{O} 2^{*}\right)$ and NO molecules, inactivates molecules of $\mathrm{H}_{2} \mathrm{O}_{2}$, chelates $\mathrm{Fe}^{2+}$-ions and oxidises $\mathrm{NADH}$.
\end{abstract}

\section{Introduction}

Orthosiphon stamineus Benth. [O. aristatus (Blume) Miq., O. spicatus (Thunb.) Bak., Ocymum grandiflorum Bl.; Lamiaceae fam.] is a popular traditional medicinal plant from South Asia that is used to treat a wide range of diseases. In Indonesia, $O$. stamineus, or kumis kucing, is used to treat rheumatism, diabetes, hypertension, tonsillitis, epilepsy, menstrual disorders, and sexually transmitted diseases; in Vietnam, for kidney and liver stones, hepatitis, colds, and inflammatory diseases; in Myanmar as a secho or myitshwe for disorders of the genitourinary system and in the traditional medicine of Java for hypertension (Ohashi et al., 2000). In Japan, O. stamineus is used as a Java tea or neko no hige for cleansing (detoxification) of the organism (Awale et al., 2004). Because of its popularity and demonstrated effectiveness, phytochemical and pharmacological research on $O$. stamineus has been carried out since the 1930s.

Chemical studies of $O$. stamineus have isolated di- and triterpenes (Awale et al., 2004; Tezuka et al., 2000), carotenoids (Kudritskaya et al., 1987) and essential oils (Hossain et al., 2008). Phenolic compounds of $O$. stamineus were detected, including phenylpropanoids, flavones, flavonols, coumarins and chromens (Akowuah et al., 2005; Matsubara et al.,
1999; Sumaryono et al., 1991).

Pharmacological studies of extracts and individual compounds from $O$. stamineus have shown biological activity including antimicrobial, antifungal (Hossain et al., 2008), hypoglycaemic, diuretic, litolytic, saluretic (Dharmaraj et al., 2006), anti-inflammatory (Awale et al., 2003), antioxidant (Akowuah et al., 2005), cytotoxic (Tezuka et al., 2000) and hypotensive (Matsubara et al., 1999) properties.

Commercial raw material of $O$. stamineus consists of dried leaves and hops of shoots, which were pre-fermented within 24-36 hours and then quickly dried. This treatment increased the extractability of this plant material. During fermentation, the raw material turns from dark green to dark brown. The nature of the dark pigment of fermented $O$. stamineus leaves has not previously been investigated, but it is probably similar to the melanoidin from fermented Camelia sinensis leaves (black tea) (Sava et al., 2001).

In this study, we present the results of a physicochemical investigation of melanoidin pigment from fermented $O$. stamineus leaves and an examination of its antioxidant properties using in vitro methods.

\section{Materials and Methods}

General 
Elemental analysis (CHNS/O) was performed in a 2400 Series II elemental analyser (Perkin Elmer, USA). Potentiometric titration was performed on a Metron automatic titrator (Germany). Spectrophotometric analysis was performed on SF2000 UV-Vis spectrophotometer (Lomo, Russian Federation). Size-exclusion chromatography (SEC) was performed on a Sephadex G-150 column (120 × $1.5 \mathrm{~cm}$, Pharmacia, Sweden) coupled to an SF-2000 UV-Vis flow-detector (Lomo, Russian Federation) at $280 \mathrm{~nm} .0 .3 \% \mathrm{NaCl}$ was used as an eluent. Preliminary calibration of the column was conducted using standard dextrans of different molecular weights $\left(\mathrm{M}_{\mathrm{w}}\right.$ $2000,100,10 \mathrm{kDa})$ and raffinose $\left(\mathrm{M}_{\mathrm{w}} 0.5 \mathrm{kDa}\right)$. The molecular weights were calculated using a calibration curve. FTIR spectra were determined using a Fouriertransform infrared spectrometer FT-801 (Simex, Russian Federation) using $\mathrm{KBr}$ pellets in the frequency range $4000-600 \mathrm{~cm}^{-1}$. The substance was ground with spectroscopic grade $\mathrm{KBr}$ powder and pressed into 1-mm pellets for FT-IR measurement.

\section{Plant material}

Green and fermented aerial parts of Orthosiphon stamineus Benth. (Lamiaceae family) were obtained from Trisko Co., Indonesia (productionrun No. B105346). The identity of the plant was kindly identified by Prof. Dr. Tamara A. Aseeva (Laboratory of Botany, Institute of General and Experimental Biology, Russia). Voucher specimens are deposited in the herbarium of Department of Biologically Active Substances, Institute of General and Experimental Biology, Russia.

\section{Analytical methods}

Physicochemical characteristics of melanoidin were determined according to the following methods: total sugar content - anthrone-sulphuric method with D-glucose as standard (Olennikov et al., 2006) and protein content using the Bradford method with bovine serum albumin as a standard (Bradford, 1976). The carboxyl group content and total phenol group content were determined using potentiometric titration according to the method of Koroleva et al. (2007). Carbonyl group content was determined using the 2,4dinitrophenylhydrazine method with acetophenone as a standard (Lappin \& Clark, 1951), and pyrocatechol group content was determined using the $\mathrm{FeSO}_{4} /$ tartrate method with pyrocatechol as a standard (Falkehag et al., 1966). Total melanoidin content was determined using a spectrophotometry, according to the method of Santos \& Stephanopoulos (2008), and rosmarinic acid content was determined using the HPTLC-densitometric method (Fecka et al., 2007).

\section{Isolation procedures}

For isolation of $O$. stamineus melanoidin pigment (OS-M), powdered fermented leaves (700 g) were first successively extracted with $n$-hexane and chloroform to remove lipids. The defatted powder was extracted four times with distilled water at $80{ }^{\circ} \mathrm{C}$ using a solid:liquid ratio of 1:20 (w/v). The mixture was filtered and the combined water extract was concentrated under vacuum at $40{ }^{\circ} \mathrm{C}$ to a final volume of $2 \mathrm{~L}$. The concentrated extract was centrifuged (6000 $\mathrm{x} g, 20 \mathrm{~min}$ ). The supernatant was treated with Sevag reagent (mixture of chloroform and $n$-butanol 4:1) to remove proteins, dialysed $(72 \mathrm{~h})$, and concentrated under vacuum at $40{ }^{\circ} \mathrm{C}$ to a final volume of $500 \mathrm{~mL}$. The resulting solution was acidified with concentrated $\mathrm{H}_{2} \mathrm{SO}_{4}$ to a final concentration of $1 \%$ and stored for $6 \mathrm{~h}$ at $10{ }^{\circ} \mathrm{C}$. The brown precipitate was centrifuged (10000 x g, $30 \mathrm{~min}$ ), washed with $1 \% \mathrm{H}_{2} \mathrm{SO}_{4}$, dissolved in $100 \mathrm{~mL}$ of $0.1 \% \mathrm{NaHCO}_{3}$ and dialysed (48 h). The undialysed fraction was dried by lyophilisation, and the powder obtained was suspended in $20 \% \mathrm{HCl}$ and stored for five days at $5{ }^{\circ} \mathrm{C}$. The mixture of powder and $\mathrm{HCl}$ was centrifuged $(6000 \times \mathrm{g}, 30 \mathrm{~min})$ and washed with $1 \% \mathrm{HCl}$; the precipitate was dissolved in $100 \mathrm{~mL}$ of $0.1 \% \mathrm{NaHCO}_{3}$ and dialysed (48 h). The undialysed part was dried by lyophilisation and dissolved in 50 $\mathrm{mL}$ of $0.1 \mathrm{M} \mathrm{Na}_{2} \mathrm{CO}_{3}$, and the solution was transferred to a Sephadex G-150 column $(110 \times 4.5 \mathrm{~cm})$ coupled to an SF-2000 UV-Vis flow detector (Lomo, Russian Federation); 6-mL fractions were collected using 0.1 $\mathrm{M} \mathrm{Na}_{2} \mathrm{CO}_{3}$ as an eluent. The fractions No. 98-118 were combined and dialysed (48 h), and the undialysed part was dried by lyophilisation, giving fractions containing OS-M. The yield of OS-M was $2.62 \mathrm{~g}$.

\section{UV-Vis spectroscopic analysis}

For determination of UV-Vis and differential spectra ten milligrams of OS-M was transferred to a volumetric flask $(25 \mathrm{~mL})$ and dissolved in $25 \mathrm{~mL}$ of a 1:1 dioxane:EtOH mixture (v/v). Then, $2 \mathrm{~mL}$ of the obtained solution was transferred into volumetric flasks $(25 \mathrm{~mL})$, one filled with $\mathrm{pH} 6.0$ buffer $(495 \mathrm{~mL}$ of $0.2 \mathrm{M} \mathrm{KH}_{2} \mathrm{PO}_{4}+113 \mathrm{~mL} 0.1 \mathrm{M} \mathrm{NaOH}+1392 \mathrm{~mL}$ of distilled water; solution $\mathrm{A}$ ) and the other with $\mathrm{pH} 12.0$ buffer (400 mL 0.1 $\mathrm{M} \mathrm{Na}_{2} \mathrm{~B}_{4} \mathrm{O}_{7}+600 \mathrm{~mL} \mathrm{0.1} \mathrm{M} \mathrm{NaOH}$; solution $\mathrm{B})$. The UV-Vis spectra were determined in a 1-cm quartz cell in the $190-800 \mathrm{~nm}$ range. Distilled water was used as a blank. To determine differential spectra, solution B was used as a sample and solution A was used as a blank.

The logarithmic slope of absorbance was 
determined using the solutions of OS-M prepared in final concentrations of $8,16,32$ and $64 \mu \mathrm{g} / \mathrm{mL}$ using $\mathrm{pH} 12.0$ buffer as a solvent. The UV-Vis spectra were determined in the 190-800 nm range. Distilled water was used as blank. For optical density data, a common logarithm was used to build a graph of optical density logarithm against wavelength. Linear regression was used to determine the regression equation, and the value of the slope was used as a logarithmic slope of absorbance. All measurements were carried out in triplicate.

The chromaticity coefficient $\mathrm{E}_{465} / \mathrm{E}_{665}$ was determined as a ratio of optical densities at 465 and $665 \mathrm{~nm}$ for the substance in $\mathrm{pH} 12.0$ buffer solutions.

For determination colour value $\mathrm{E}^{1 \%} 1 \mathrm{~cm}$ of OS-M solutions were prepared in final concentrations of $8,16,32,64,128$ and $256 \mu \mathrm{g} / \mathrm{mL}$ using $\mathrm{pH} 12.0$ buffer as a solvent. The optical densities of the solutions were determined at $195 \mathrm{~nm}$ using distilled water as a blank. The data were used to construct a graph of optical density versus concentration. After linear regression was determined, the regression equation and the colour value $\left(\mathrm{E}^{1 \%} 1 \mathrm{~cm}\right)$ were calculated as the optical density of an OS-M solution with concentration $10 \mathrm{mg} / \mathrm{mL}$ $(=1 \%)$. All measurements were carried out three times.

\section{Melanoidin-Fe-salt preparation $(O S-M-F e)$}

One hundred milligrams of OS-M was dissolved in $2 \mathrm{~mL}$ of $\mathrm{DMSO}$, and $48 \mathrm{~mL}$ of distilled water was added. Twenty milliliters of a $1 \%$ solution of $\mathrm{FeSO}_{4}$ in distilled water was added and stirred for $2 \mathrm{~h}$ at $30^{\circ} \mathrm{C}$. The reaction mixture was centrifuged (12000 x $g$, $30 \mathrm{~min}$ ), and the precipitate was washed with distilled water and dried under vacuum at $20{ }^{\circ} \mathrm{C}$. The yield of melanoidin-Fe-salt (OS-M-Fe) was $124 \mathrm{mg}$.

Aqueous extract of $\mathrm{O}$. stamineus leaves (AEOS) preparation

Powdered fermented O. stamineus leaves (200 g) were extracted three times with water at $80^{\circ} \mathrm{C}$ using a solid:liquid ratio of 1:25 (w/v). The mixture was filtered, and the combined water extracts were concentrated under vacuum at $40{ }^{\circ} \mathrm{C}$ to a final volume of $1 \mathrm{~L}$. The concentrated extract was centrifuged (6000 $\times \mathrm{g}, 20 \mathrm{~min})$, and the supernatant was dried in a ShSV-45k vacuum-drying box (KZMA, Inc., Kazan', Russia) to give dried water extract of $O$. stamineus leaves (AEOS), which was then powdered in a VSI-05 crushing machine (KZMA, Inc., Kazan', Russia). The yield of AEOS was $30.74 \mathrm{~g}$.

Antioxidant activity assays
The ability to scavenge $\mathrm{DPPH}^{*}$ free radicals was assessed as described by Asker \& Shawky (2010); the radical-scavenging activity against $\mathrm{ABTS}^{-+}$radical cation was measured using the method of Ding et al. (2010); the determination of superoxide anion scavenging activity was measured in phenazine methosulphate-nicotinamide adenine dinucleotidenitroblue tetrazolium systems using the method of Ozen et al. (2011); the NO scavenging activity was measured using the sodium nitroprusside method (Kumar et al., 2008); the $\mathrm{H}_{2} \mathrm{O}_{2}$ inactivating activity was measured using the method of Badami \& Channabasavaraj (2007); the chelating activity for $\mathrm{Fe}^{2+}$-ions was measured by the $o$-phenanthroline method (Olennikov et al., 2011a); $\beta$-carotene bleaching assay was performed in $\beta$-carotene-oleic acid-DMSO- $\mathrm{H}_{2} \mathrm{O}_{2}$-system (Olennikov et al., 2011b); the oxidation of NADH was determined by the method of Mosca et al. (1998).

\section{Statistical analysis}

All measurements were carried out in triplicate. Statistical analyses were performed using a one-way analysis of variance (ANOVA), and the significance of the mean difference was determined by Duncan's multiple range test. Differences at $p<0.05$ were considered statistically significant. The results were presented as mean values $\pm \mathrm{SD}$ (standard deviations).

\section{Results and Discussion}

The melanoidin pigment OS-M was isolated from fermented $O$. stamineus leaves using water extraction, acid hydrolysis, repeated precipitation, gel-permeation chromatography on a Sephadex G-150 column and dialysis. The physical and chemical properties of the purified melanoidin OS-M were studied. The average yield of OS-M was $0.37 \%$ (dry basis). The $O$. stamineus melanoidin, an amorphous dark-brown substance that was precipitated in alkaline and neutral solutions of $\mathrm{FeSO}_{4}$ and $\mathrm{FeCl}_{3}$ and at $\mathrm{pH}$ below 2.5-3.0 and was bleached by $\mathrm{H}_{2} \mathrm{O}_{2}, \mathrm{KMnO}_{4}$ and $\mathrm{NaOCl}$. The OS-M does not contain sugars or proteins.

The elemental composition of OS-M was as follows: $\mathrm{C}=57.14 \pm 1.14 \%, \mathrm{H}=3.92 \pm 0.07 \%$, $\mathrm{N}=2.02 \pm 0.04 \%, \mathrm{O}=36.92 \pm 0.73 \%$; notably, the presence of sulphur was not detected. The $\mathrm{C} / \mathrm{H}$ ratio of 1.21 indicates an aromatic nature (Koroleva et al., 2007). Comparative analysis of these results with the same data for black tea melanoidin (Sava et al., 2001) shows that OS-M was characterised by higher carbon content and a higher $\mathrm{C} / \mathrm{H}$ value, indicating a higher level of aromaticity for $O$. stamineus melanoidin.

Functional group analysis demonstrated that 
OS-M contained $9.31 \pm 0.32 \%$ carboxylic groups, $7.07 \pm 0.24 \%$ carbonyl groups, $8.67 \pm 0.28 \%$ phenolic hydroxyl groups and $3.52 \pm 0.11 \%$ pyrocatechol groups. The SEC of OS-M on Sephadex G-150 was visible as a single peak, which corresponded to a molecular weight of $4.4 \mathrm{kDa}$.

The absorption spectrum of OS-M was outwardly simple and contained a single strong band at $228 \mathrm{~nm}$ and two weak shoulders at 267 and $337 \mathrm{~nm}$. The band at 228 and the shoulder at $267 \mathrm{~nm}$ were the primary and secondary $\mathrm{B}$-band resulting from $\mathrm{A}_{1 \mathrm{~g}}{ }^{\prime} \rightarrow$ $\mathrm{B}_{1 \mathrm{u}}{ }^{\prime}$ and $\mathrm{A}_{1 \mathrm{~g}}{ }^{\prime} \rightarrow \mathrm{B}_{2 \mathrm{u}}{ }^{\prime}$ transition types, respectively. The appearance of the shoulder at $337 \mathrm{~nm}$ (K-band) was the result of a lengthening of the $\pi$-conjugation chain. The absorption spectra of OS-M in alkaline media displayed a slight reduction in the intensity of the primary B-band and its weak hypsochromic shift to $224 \mathrm{~nm}$. The secondary B-band (267 nm) and K-band (337 nm) were marked by an increase in intensity and a bathochromic shift to 271 and $365 \mathrm{~nm}$, respectively. These changes were caused by the ionisation of phenolic hydroxyl groups in alkaline medium. The differential spectrum of OS-M (alkaline solution vs. neutral solution) displayed three bands at 261, 301 and $378 \mathrm{~nm}$ and a number of very weak bands and shoulders in the visible region $(487,587,654,702,766 \mathrm{~nm})$. The origin of these bands was the result of bathochromic shifts of the primary and secondary B-bands and K-bands in the initial spectra. In the case of OS-M, the intensity of the band was maximal at $378 \mathrm{~nm}$ as a result of the presence of a sufficient quantity of $\alpha$-carbonyl containing groups in the melanoidin structure.

A plot of the logarithm of absorbance versus wavelength for an alkaline solution of OS-M was described by linear dependence. The dependence was linear regardless of the concentration of the melanoidin solution. However, it should be noted that the linearity of this dependence increased as the concentration of melanoidin increased. For example, for OS-M solutions with concentrations of $8,16,32$ and $64 \mu \mathrm{g} / \mathrm{mL}$, the coefficients of determination $\left(r^{2}\right)$ were $0.9952,0.9981,0.9985$ and 0.9992 , respectively. The linearity of this dependence was observed in the wavelength range from 230 to $700 \mathrm{~nm}$. The values of the logarithmic slope of absorbance for solutions with different concentrations were similar $(-0.0034$ to -0.0038). Therefore, to determine this characteristic, we recommend an arithmetic mean value using a series of solutions with different concentrations of melanoidin. The value of the logarithmic slope of absorbance for OS-M defined in this way was -0.00365 , similar to those previously calculated for other melanoidins (Ellis \& Griffits, 1974).

The value of the chromaticity coefficient $\left(\mathrm{E}_{465} /\right.$ $\left.\mathrm{E}_{665}\right)$ of OS-M was $4.47 \pm 0.11$, indicating a small amount of aliphatic fragments and high content of aromatic components. The colour value of the OS-M $\left(\mathrm{E}^{1 \%} 1 \mathrm{~cm}\right)$ was $81.25 \pm 2.59$, higher than the colour value for the general pigment (45.0) and Osmanthus fragrans' seed melanoidin (60.24) (Wang et al., 2006).

The FTIR spectrum of OS-M indicates the presence of bands similar to those of other melanoidins (Bilińska, 1996). A broad band at $3400 \mathrm{~cm}^{-1}$ can be attributed to stretching vibrations of $\mathrm{OH}$ and $\mathrm{NH}_{2}$ groups, and weak vibrations at 2929 and $2858 \mathrm{~cm}^{-1}$ are assigned to stretching vibrations of aliphatic $\mathrm{C}=\mathrm{H}, \mathrm{CH}_{2}$ and $\mathrm{CH}_{3}$ groups. The strong absorbances at 1720 and $1650 \mathrm{~cm}-1$ were recognised as vibrations of free carboxylic groups and of aromatic $\mathrm{C}=\mathrm{C}$ and/or $\mathrm{C}=\mathrm{O}$ groups, respectively. $\mathrm{A}$ small amount of aliphatic fragments and the high degree of aromaticity in the structure of OS-M was confirmed by the elemental analysis, $\mathrm{C} / \mathrm{H}$ ratio and the value of chromaticity coefficient. The absence of bands in the 1610-1625 and $960-970 \mathrm{~cm}^{-1}$ region indicated a low level of double bonds in the structure of melanoidin. The FTIR spectrum of OS-M also contained bands at $1515 \mathrm{~cm}^{-1}$ (aromatic rings C-C stretching, NH deformation in amide II), $1443 \mathrm{~cm}^{-1}$ (deformation of aliphatic $\mathrm{C}-\mathrm{H}$ and a stretching of phenolic $\mathrm{OH}$ and symmetric stretching of $\left.\mathrm{COO}^{-}\right), 1230 \mathrm{~cm}^{-1}(\mathrm{C}-\mathrm{H}$ deformations and $\mathrm{C}-\mathrm{O}$ stretching in phenolic groups), 1207 $\mathrm{cm}^{-1}$ (stretching of ester C-O-C and valence vibrations of phenolic C-O groups), $1125 \mathrm{~cm}^{-1}$ (ring breathing and C-O groups stretching), $1056 \mathrm{~cm}^{-1}$ (aromatic esters), 880, 861, $834,778 \mathrm{~cm}^{-1}$ (vibrations of $\mathrm{H}$-atoms in aromatic rings), 673 , and $595 \mathrm{~cm}^{-1}$ (Bilińska, 1996).

Table 1. Antioxidant activity of OS-M, rosmarinic acid and aqueous extract of Orthosiphon stamineus leaves (AEOS)., b

\begin{tabular}{|c|c|c|c|c|c|c|c|}
\hline Substance & $\begin{array}{c}\text { DPPH, } \\
\mathrm{IC} 50, \mu \mathrm{g} / \mathrm{mL}\end{array}$ & $\begin{array}{c}\text { ABTS, } \\
\text { IC } 50, \mu \mathrm{g} / \mathrm{mL}\end{array}$ & $\begin{array}{c}\text { SSA, } \\
\mathrm{IC} 50, \mu \mathrm{g} / \mathrm{mL}\end{array}$ & $\begin{array}{c}\text { NOSA, } \\
\text { IC } 50, \mu \mathrm{g} / \mathrm{mL}\end{array}$ & $\begin{array}{c}\text { HIA, } \\
\text { IC } 50, \mu \mathrm{g} / \mathrm{mL}\end{array}$ & $\begin{array}{c}\text { FCA, } \\
\mathrm{IC} 50, \mu \mathrm{g} / \mathrm{mL}\end{array}$ & $\begin{array}{c}\text { CBA, } \\
\mathrm{IC} 50, \mu \mathrm{g} / \mathrm{mL}\end{array}$ \\
\hline OS-M & $7.91 \pm 0.24$ & $3.36 \pm 0.09$ & $43.49 \pm 1.39$ & $22.22 \pm 0.68$ & $13.36 \pm 0.37$ & $11.41 \pm 0.34$ & $12.81 \pm 0.38$ \\
\hline Rosmarinic acid & $3.91 \pm 0.07$ & $1.78 \pm 0.04$ & $10.02 \pm 0.31$ & $6.96 \pm 0.21$ & $3.52 \pm 0.09$ & $>500$ & $42.89 \pm 0.81$ \\
\hline AEOS & $15.48 \pm 0.46$ & $11.85 \pm 0.35$ & $11.38 \pm 0.30$ & $8.11 \pm 0.24$ & $185.73 \pm 5.57$ & $22.31 \pm 0.67$ & $41.80 \pm 1.11$ \\
\hline Gallic acid ${ }^{c}$ & $0.98 \pm 0.03$ & $0.311 \pm 0.009$ & $76.42 \pm 2.29$ & $7.24 \pm 0.22$ & $5.14 \pm 0.14$ & $>500$ & $12.30 \pm 0.37$ \\
\hline
\end{tabular}

${ }^{\text {aDPPH}}{ }^{\cdot}$ radical-scavenging assay (DPPH), $\mathrm{ABTS}^{\cdot+}$ radical cation-scavenging assay (ABTS), superoxide-anion scavenging assay (SSA), NO scavenging

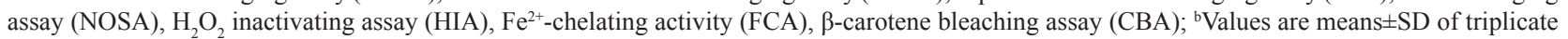
measurements; 'Reference compound. 
On the basis of these studies, we concluded that the biopolymer isolated from the fermented leaves of $O$. stamineus was melanoidin.

Comparative analysis of the melanoidin content in native and fermented leaves of $O$. stamineus showed that native (green) leaves do not contain melanoidin, with the exception of stems, which contain $0.124 \mathrm{mg} / \mathrm{g}$ (from dry weight) of melanoidin. The formation of melanoidin in the leaves of $O$. stamineus is therefore due to the fermentation process. The highest content of melanoidin was characteristic of old leaves $(4.37 \mathrm{mg} / \mathrm{g})$; melanoidin content in young leaves and stems was 3.21 and $1.43 \mathrm{mg} / \mathrm{g}$, respectively.

Experimental investigations of the antioxidant activity of $O$. stamineus melanoidin (OS-M) were conducted using the traditional assays: DPPH radical-scavenging assay $(\mathrm{DPPH}), \mathrm{ABTS}^{\cdot+}$ radical cation-scavenging assay (ABTS), superoxide-anion scavenging assay (SSA), NO scavenging assay (NOSA), $\mathrm{H}_{2} \mathrm{O}_{2}$ inactivating assay (HIA), $\mathrm{Fe}^{2+}$-chelating activity (FCA), and $\beta$-carotene bleaching assay (CBA) (Table 1). All experiments included determination and comparative estimation of the same antioxidant factors for rosmarinic acid, the predominant component of $O$. stamineus with known antioxidant activity (Akowuah et al., 2005), aqueous extract of $O$. stamineus leaves (AEOS) characterised by co-presence of rosmarinic acid (56.34 $\pm 1.12 \mathrm{mg} / \mathrm{g}$ from dry AEOS weight) and melanoidin (12.16 $\pm 0.14 \mathrm{mg} / \mathrm{g}$ from dry AEOS weight) and gallic acid as an antioxidant reference compound. The radical-scavenging activity of OS-M against DPPH and $\mathrm{ABTS}^{-+}$radicals was very high, with $\mathrm{IC} 50=7.91$ and $3.36 \mu \mathrm{g} / \mathrm{mL}$, respectively. The same parameters for rosmarinic acid were $3.91 \mu \mathrm{g} / \mathrm{mL}\left(\mathrm{DPPH}^{\circ}\right)$ and 1.78 $\mu \mathrm{g} / \mathrm{mL}\left(\mathrm{ABTS}^{*}\right)$; for gallic acid the values were 0.98 $\mu \mathrm{g} / \mathrm{mL}\left(\mathrm{DPPH}^{\circ}\right)$ and $0.311 \mu \mathrm{g} / \mathrm{mL}\left(\mathrm{ABTS}^{\cdot+}\right)$. This data classifies OS-M as a radical scavenger. The high radicalscavenging activity of melanoidins has previously been shown for other representative melanoidins ( $\mathrm{Tu}$ et al., 2009).

The superoxide-anion scavenging activity of OS-M was IC50 $43.49 \mu \mathrm{g} / \mathrm{mL}$, higher than the activity of gallic acid $(76.42 \mu \mathrm{g} / \mathrm{mL})$ but lower than the activity of rosmarinic acid $(10.02 \mu \mathrm{g} / \mathrm{mL})$ and AEOS $(11.38 \mu \mathrm{g} /$ $\mathrm{mL})$. This kind of antioxidant action was previously determined for synthetic (DOPA-, TPT-, Leuenk- and Tyr-Gly-melanoidins) (Mosca et al., 1998) and natural melanoidins (Sava et al., 2001). The superoxide anionscavenging activity of OS-M is enabled by its stable free radical (Mosca et al., 1998).

The activity of OS-M in the NO scavenging assay was characterised as medium (IC50 $22.22 \mu \mathrm{g}$ / $\mathrm{mL}$ ) because the activity of rosmarinic and gallic acids and AEOS were quite high $(6.96,7.24,8.11 \mu \mathrm{g} / \mathrm{mL}$, respectively).
The effect of OS-M on hydrogen peroxide $\left(\mathrm{H}_{2} \mathrm{O}_{2}\right)$ inactivation was higher than for WEOS; the IC50 values of OS-M and AEOS were 13.36 and $185.73 \mu \mathrm{g} /$ $\mathrm{mL}$, respectively. However, rosmarinic acid provoked more effective inactivation of $\mathrm{H}_{2} \mathrm{O}_{2}$ molecules (3.52 $\mu \mathrm{g} / \mathrm{mL})$. The reduced activity of AEOS was probably caused by the presence of other accompanying components of the $O$. stamineus extracts. Analogous parameters determined previously for synthetic melanoidin and melanoidin from Aspergillus nidulans were significantly lower - 57.91 and $186.17 \mu \mathrm{g} / \mathrm{mL}$, respectively (Goncalves \& Pombeiro-Sponchiado, 2005). OS-M can therefore be considered a good $\mathrm{H}_{2} \mathrm{O}_{2}$ inactivator.

Reports of melanoidins as good chelators of metal ions (Fogarty \& Tobin, 1996) led to our examination of the $\mathrm{Fe}^{2+}$-chelating activity of OS-M. Experimental data showed that $O$. stamineus melanoidin expressed chelating action on $\mathrm{Fe}^{2+}$-ions (IC50 $11.41 \mu \mathrm{g}$ / $\mathrm{mL}$ ) and was more effective than low-molecular-weight compounds. For example, the chelating activity of rosmarinic and gallic acids as an IC50 was $>500 \mu \mathrm{g} / \mathrm{mL}$. The presence of this kind of activity for AEOS (IC50 $22.31 \mu \mathrm{g} / \mathrm{mL}$ ) was partially caused by the presence of OS-M. $\mathrm{Fe}^{2+}$ ions react with melanoidin to form $\mathrm{Fe}^{2+}$ melanoidin complexes that were confirmed by FTIRspectroscopy. Some changes in the FTIR spectra of $\mathrm{Fe}^{2+}$ melanoidin complex (OS-M-Fe) were observed. The band at $1714 \mathrm{~cm}^{-1}$ disappeared, indicating the formation of chemical bonds between free carboxylic groups and $\mathrm{Fe}^{2+}$-ions. The FTIR spectrum of OS-M-Fe was also characterised by the presence of two intense bands at 1392 and $1274 \mathrm{~cm}^{-1}$, which were initially absent in the spectra of melanoidin. All detected changes indicated that $O$. stamineus melanoidin reacted with $\mathrm{Fe}^{2+}$-ions to form a $\mathrm{Fe}^{2+}$-melanoidin complex, removing $\mathrm{Fe}^{2+}$-ions and limiting the possibility of their participation in the lipid peroxidation processes.

The examination of the influence of OS-M on the oxidative destruction of $\beta$-carotene in the oleic acid-DMSO- $\mathrm{H}_{2} \mathrm{O}_{2}$ system demonstrated a high value of antioxidant activity, with IC50 $12.81 \mu \mathrm{g} / \mathrm{mL}$, similar to the $12.30 \mu \mathrm{g} / \mathrm{mL}$ value of parameter for gallic acid. The efficiency of rosmarinic acid in this assay was slightly lower $(42.89 \mu \mathrm{g} / \mathrm{mL})$. One feature of the $\beta$-carotene bleaching assay is the ability to investigate the influence of OS-M on the presence of a complex of damaging factors, including $\mathrm{H}_{2} \mathrm{O}_{2}, \mathrm{O}^{2 \cdot \bullet}, \mathrm{OH}^{\cdot}$, and alkylradicals that form in this in vitro system. Our results were shown that $O$. stamineus melanoidin is a highly effective antioxidant.

It is known that DOPA-melanoidin can oxidise $\mathrm{NADH}$ through the action of free radicals in the polymer structure (Gan et al., 1974). We assayed the oxidising properties of $O$. stamineus melanoidin and 
established that OS-M influenced NADH in a dosedependent manner (Figure 1). In the study, the degree of autoxidation of NADH was $3.52 \%$. The introduction of various concentrations of melanoidin increased this value to $4.10,10.02$ and $29.61 \%$ for the melanoidin concentrations of 33,83 and $167 \mu \mathrm{g} / \mathrm{mL}$, respectively.

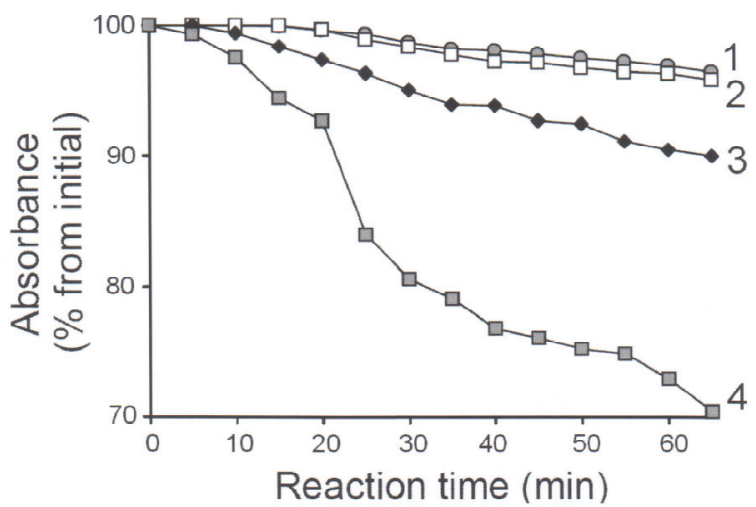

Figure 1. NADH oxidation by OS-M. (1) NADH, (2) NADH + OS-M (33 $\mu \mathrm{g} / \mathrm{mL})$, (3) NADH + OS-M (83 $\mu \mathrm{g} / \mathrm{mL})$, (4) $\mathrm{NADH}+\mathrm{OS}-\mathrm{M}(167 \mu \mathrm{g} / \mathrm{mL})$.

\section{Conclusions}

We investigated the pigment OS-M, isolated from fermented $O$. stamineus leaves, by a physicalchemical analysis. Elemental analysis, functional group analysis, UV-Vis- and FTIR-spectroscopy indicated the aromatic nature of OS-M and confirmed its membership in the class of melanoidin pigments.

The study of the antioxidant activity of OS-M using traditional in vitro methods indicated that OS-M strongly scavenges free radicals (DPPH', $\mathrm{ABTS}^{\cdot+}, \mathrm{O}^{2 \cdot-}$ ) and NO molecules, inactivates hydrogen peroxide, chelates $\mathrm{Fe}^{2+}$-ions and oxidises NADH. Comparative analysis of the data indicates that in some cases, the antioxidant activity of melanoidin met or exceeded the activity of rosmarinic acid, the known antioxidant compound from O. stamineus leaves. For example, the $\mathrm{Fe}^{2+}$-chelating activity $\mathrm{OS}-\mathrm{M}$ and the antioxidant activity in the $\beta$-carotene bleaching assay were significantly higher than that of rosmarinic acid. Our data add to the information about compounds from $O$. stamineus leaf extracts that exhibit antioxidant activity. We hypothesise that the presence of melanoidin in fermented $O$. stamineus leaves also contributes to the inhibitory effect of its extracts on lipid peroxidation processes.

\section{Acknowledgment}

The authors thank the Lavrent'ev's Foundation for financial support (grant No 6.22).

\section{References}

Akowuah GA, Ismail Z, Norhayati I, Sadikun A 2005. The effects of different extraction solvents of varying polarities on polyphenols of Orthosiphon stamineus and evaluation of the free radical-scavenging activity. Food Chem 93: 311-317.

Asker MMS, Shawky BT 2010. Structural characterization and antioxidant activity of an extracellular polysaccharide isolated from Brevibacterium otitidis BTS 44. Food Chem 123: 315-320.

Awale S, Tezuka Y, Banskota AH, Adnyana IK, Kadota S 2003. Highly-oxygenated isopimaran-type diterpenes from Orthosiphon stamineus of Indonesia and their nitric oxide inhibitory activity. Chem Pharm Bull 51: 268-275.

Awale S, Tezuka Y, Kobayashi M, Ueda J, Kadota S 2004. Neoorthosiphonone A; a nitric oxide (NO) inhibitory diterpene with new carbon skeleton from Orthosiphon stamineus. Tetrahedr Lett 45: 1359-1362.

Badami S, Channabasavaraj KP 2007. In vitro antioxidant activity of thirteen medicinal plants of India's Western Ghats. Pharm Biol 45: 392-396.

Bilińska B 1996. Progress in infrared investigations of melanin structures. Spectrochim Acta A 52: 1157-1162.

Bradford MM 1976. A rapid and sensitive method for the quantification of microgram quantities of protein utilizing the principle of protein-dye binding. Anal Biochem 72: 248-254.

Dharmaraj S, Hossain MA, Zhari S, Harn GL, Ismail Z 2006. The use of principal component analysis and self-organizing map to monitor inhibition of calcium oxalate crystal growth by Orthosiphon stamineus extract. Chemometr Intell Lab Syst 81: 21-28.

Ding H, Chou T, Liang C 2010. Antioxidant and antimelanogenic properties of rosmarinic acid methyl ester from Origanum vulgare. Food Chem 123: 254262.

Ellis DH, Griffiths DA 1974. The location and the analysis of melanins in the cell walls of some soil fungi. Can J Microbiol 20: 1379-1386.

Falkehag SI, Marton J, Adler E 1966. Chromophores in craft lignin. In Marton J (ed.) Lignin structure and reactions. Advances in Chemistry. Ser. 59. Washington: American Chemical Society, p. 75-89.

Fecka I, Raj D, Krauze-Baranowska M 2007. Quantitative determination of four water-soluble compounds in herbal drugs from Lamiaceae using different chromatographic techniques. Chromatographia 66: 87-93.

Fogarty RV, Tobin JM 1996. Fungal melanins and their interaction with metals. Enzyme Microb Technol 19: 311-317.

Gan EV, Haberman HF, Menon IA 1974. Oxidation of NADH by melanin and melanoproteins. Biochim Biophys 
Acta Enzymol 370: 62-69.

Goncalves RCR, Pombeiro-Sponchiado SR 2005. Antioxidant activity of the melanin pigment extracted from Aspergillus nidulans. Biol Pharm Bull 28: 1129. 1131.

Hossain MA, Ismail Z, Rahman A, Kang SC 2008. Chemical composition and anti-fungal properties of the essential oils and crude extracts of Orthosiphon stamineus Benth. Ind Crop Prod 27: 328-334.

Koroleva OV, Kulikova NA, Alekseeva TN, Stepanova EV, Davidchuk VN, Belyaeva EY, Tsvetkova EA 2007. A comparative characterization of fungal melanin and the humin-like substances synthesized by Cerrena maxima 0275. Appl Biochem Microbiol 43: 61-67.

Kudritskaya SE, Fishman GM, Zagorodskaya LM, Chikovani DM 1987. Carotenoids of Orthosiphon stamineus. Chem Nat Comp 23: 767-768.

Kumar S, Kumar D, Manjusha, Saroha K, Singif N, Vashishta B 2008. Antioxidant and free radical scavenging potential of Citrullus colocynthis (L.) Schrad. methanolic fruit extract. Acta Pharm 58: 215-220.

Lappin GR, Clark LC 1951. Colorimetric method for determination of traces of carbonyl compounds. Anal Chem 23: 541-542.

Matsubara T, Bohgaki T, Watarai M, Suzuki H, Ohashi K, Shibuya H 1999. Antihypertensive action of methylripariochromene A from Orthosiphon aristatus, an Indonesian traditional medicinal plant. Biol Pharm Bull 22: 1083-1088.

Mosca L, Blarzino C, Coccia R, Foppoli C, Rosei AM 1998. Melanins from tetrahydroisoquinolines: Spectroscopic characteristics, scavenging activity and redox transfer properties. Free Rad Biol Med 24: 161-167.

Ohashi K, Bohgaki T, Shibuya H 2000. Antihypertensive substance in the leaves of Kumis kucing (Orthosiphon aristatus) in Java island. Yakugaku Zasshi 120: 474-482.

Olennikov DN, Agafonova SV, Stolbikova AV, Rokhin AV 2011a. Melanin of Laetiporus sulphureus (Bull.: Fr.) Murr sterile form. Appl Biochem Microbiol 47: 298303.

Olennikov DN, Tankhaeva LM, Agafonova SV 2011b. Antioxidant components of Laetiporus sulphureus (Bull.: Fr.) Murr. fruit bodies. Appl Biochem Microbiol
47: 419-425.

Olennikov DN, Tankhaeva LM, Samuelsen AB 2006. Quantitative analysis of polysaccharides from Plantago major leaves using the Dreywood method. Chem Nat Comp 42: 265-268.

Ozen T, Demirtas I, Aksit H 2011. Determination of antioxidant activities of various extracts and essential oil compositions of Thymus praecox subsp. skorpilii var. skorpilii. Food Chem 124: 58-64.

Santos CNS, Stephanopoulos G 2008. Melanin-based highthroughput screen for L-tyrosine production in Escherichia coli. Appl Environ Microbiol 74: 11901197.

Sava VM, Yang S, Hong M, Yang P, Huang GS 2001. Isolation and characterization of melanic pigments derived from tea and tea polyphenols. Food Chem 73: 177-184.

Sumaryono W, Proksch P, Wray V, Witte L, Hartmann T 1991. Qualitative and quantitative analysis of the phenolic constituents from Orthosiphon aristatus. Planta Med 57: 176-180.

Tezuka Y, Stampoulis P, Banskota AH, Awale S, Tran KQ, Saiki I, Kadota S 2000. Constituents of the Vietnamese medicinal plant Orthosiphon stamineus. Chem Pharm Bull 48: 1711-1719.

Tu Y, Sun Y, Tian Y, Xie M, Chen J 2009. Physicochemical characterization and antioxidant activity of melanin from the muscles of Taihe Black-bone silky fowl (Gallus gallus domesticus Brisson). Food Chem 114: 1345-1350.

Wang H, Pan Y, Tang X, Huang Z 2006. Isolation and characterization of melanin from Osmanthus fragrans' seeds. $L W T$ 39: 496-502.

\section{*Correspondence}

Daniil N. Olennikov

Laboratory of Medical and Biological Research, Institute of General and Experimental Biology, Siberian Division, Russian Academy of Sciences

Sakh'yanovoy str., 6, Ulan-Ude, Russian Federation, 670047 oldaniil@rambler.ru

Tel.: +7902 1600627

Fax: +7 3012433430 